Original Research Article

\title{
Correlation between endothelial dysfunction, inflammatory status, oxidative stress and total (nitrite/ nitrate) in subjects with diabetes mellitus type 2
}

\author{
C. Prabhakar Reddy ${ }^{1}$, Uday Kumar Chiranjeevi ${ }^{2 *}$, Chandrasekhar N. ${ }^{1}$, Kiran Kishore K. ${ }^{3}$, \\ Krishna P. V. ${ }^{4}$
}

\begin{abstract}
${ }^{1}$ Department of Clinical
Pharmacology and Therapeutics, Nizam's Institute of Medical

Sciences, Hyderabad,

Telangana, India

${ }^{2}$ Department of Pharmacology,

ASRAM Medical College,

Eluru, Andhra Pradesh, India

${ }^{3}$ Department of Clinical

Pharmacology, Jeevan Scientific

Technology Limited,

Hyderabad, Telangana, India

${ }^{4}$ Consultant Clinical

Pharmacologist, Bharat Biotech

International Limited,

Hyderabad, Telangana, India
\end{abstract}

Received: 22 August 2017

Accepted: 26 August 2017

*Correspondence to:

Dr. Uday Kumar Chiranjeevi,

Email: cptnims@gmail.com

Copyright: () the author(s), publisher and licensee Medip Academy. This is an openaccess article distributed under the terms of the Creative Commons Attribution NonCommercial License, which permits unrestricted noncommercial use, distribution, and reproduction in any medium, provided the original work is properly cited.

\begin{abstract}
Background: Diabetes Mellitus is a systemic metabolic disorder associated with Endothelial dysfunction and increased systemic inflammatory state with oxidative stress leading to increased Cardiovascular risk. This study planned to correlate the level of Endothelial dysfunction with oxidative stress and inflammatory status.

Methods: Study was conducted in 60 Diabetes Mellitus subjects of both genders with duration of more than two years. Endothelial dysfunction assessed as Augmentation Pressure and Augmentation Index generated from Radial artery waveforms by tonometer using Spygmocor PWA system. Plasma Total Nitrite/ Nitrate, High sensitive C - Reactive Protein, Malondialdehyde and Glutathione were measured.

Results: Out of total 60 Diabetes Mellitus subjects 16 subjects were with Coronary Artery Disease. There was no significant difference in High sensitive C - Reactive Protein, Glutathione, Malondialdehyde and Total Nitrite/ Nitrate between Diabetes Mellitus with Coronary Artery Disease and without Coronary Artery Disease, however significant difference $(\mathrm{p}=0.02)$ was observed Augmentation Pressure between Diabetic alone (12.8 $\pm 5.19 \mathrm{~mm}$ of Mercury) and diabetics with Coronary Artery Disease $(16.13 \pm 33.47 \mathrm{~mm}$ of Mercury) and Augmentation Index $(\mathrm{p}=0.04)$ between Diabetic alone $(29.8 \pm 5.68 \mathrm{~mm}$ of

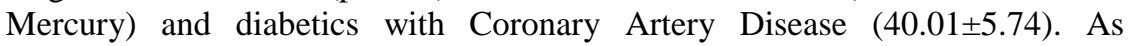
endothelial function is age dependent the subjects were divided into three age groups (20-40 years, 40-60 years and more than 60 years). High sensitive C Reactive Protein, Glutathione, Malondialdehyde, Total Nitrite/ Nitrate and Augmentation Index did not differ in the three age groups while Augmentation Pressure $(\mathrm{p}=0.0096)$ showed significant difference between age group 20-40 years $(10.59 \pm 3.24)$ and age group more than 60 years $(15.83 \pm 3.92)$.

Conclusions: There is significant endothelial dysfunction observed in Diabetes Mellitus subjects and Diabetes Mellitus with coronary artery disease showed greater endothelial dyfunction. Thereby concluding that Diabetes Mellitus subjects were at higher risk for development of coronary artery disease and as endothelial dysfunction is an early event, it may have some prognostic value.
\end{abstract}

Keywords: Augmentation pressure, Augmentation index, Diabetes mellitus, Endothelial dysfunction, Oxidative stress

\section{INTRODUCTION}

Globally, an estimated 422 million adults are living with Diabetes Mellitus (DM), according to the latest 2016 data from the World Health Organization. ${ }^{1}$ Diabetes prevalence is increasing rapidly and the number is projected to almost double by $2030 .^{2}$ India, the second most populous country 
of the world, has been severely affected by the global diabetes epidemic. ${ }^{3}$

Diabetes Mellitus is a metabolic disorder characterized by increased mortality rates and importantly implicated in the atherogenetic process. The manifestation of endothelial dysfunction is not only associated with cardiovascular disease but may precede its development, as shown in a study of offspring of hypertensive patients. ${ }^{4}$

The Endothelial dysfunction is characterized by reduction of the bioavailability of vasodilators, particularly nitric oxide (NO), and/or an increase in endothelium-derived contracting factors. ${ }^{5}$ The resulting imbalance leads to an impairment of endothelium-dependent vasodilatation, which is the functional characteristic of endothelial dysfunction. Endothelial cells (ECs) synthesize and release different molecules that orchestrate metabolic, vascular, and cellular responses. Among them, nitric oxide (NO) is a key regulatory molecule of paramount importance for endothelial function and vascular tone relaxation. ${ }^{6,7}$ Reduced endothelial cell nitric oxide synthase (eNOS) expression and/or NO bioavailability are associated with decreased EC survival and with endothelial dysfunction. ${ }^{8}$ The regulation of NO metabolism is particularly important in diabetes mellitus, since the activation of eNOS has been demonstrated to be under the insulin control. ${ }^{9,10}$

Diabetes is also associated with a systemic inflammatory state that may impair endothelial function and contribute to atherosclerosis. ${ }^{11} \mathrm{~A}$ diabetic patient there is an increase of circulating levels of inflammatory markers. ${ }^{12-14}$ Moreover, higher levels of inflammatory markers are a predictor of increased cardiovascular risk in diabetic patients and on the other hand, augmented levels of circulating inflammatory markers also relate to the incidence of diabetes mellitus. ${ }^{15,16}$ Oxidative stress, caused by the overproduction of Reactive Oxygen Species (ROS) plays an important role in the activation of pathogenic pathways involved in diabetic complications. Increased oxidative stress in the vasculature is a major contributor of endothelial dysfunction in DM via the superoxide production and impairment of NO bioavailability in the vascular wall. The concept of mild chronic vascular inflammation as part of the pathophysiology of cardiovascular disease, most importantly hypertension and atherosclerosis, has been well accepted. Indeed, there are links between vascular inflammation, endothelial dysfunction and oxidative stress. ${ }^{17}$

The prevalence of diabetes mellitus is rising worldwide and has reached epidemic dimensions. Diabetes mellitus places patients at high cardiovascular risk. Diabetes and its associated complications have become a public health problem of considerable magnitude. Cardiovascular disease causes most of the excess morbidity and mortality in diabetes mellitus. Adults with diabetes are at a 2- to 4fold increased risk of cardiovascular events relative to those without diabetes. ${ }^{18}$ Cardiovascular disease accounts for up to $80 \%$ of premature excess mortality in Diabetes mellitus. ${ }^{19}$ Both systemic and coronary endothelial dysfunction have been demonstrated to be independent predictors of cardiovascular events. ${ }^{20,21}$

So, this study was conducted to correlate endothelial Dysfunction with inflammatory markers, oxidative stress and Nitric Oxide levels in subjects diagnosed with Type 2 Diabetes Mellitus.

\section{METHODS}

The study was conducted with NIMS Institutional Ethics Committee approved protocol and in compliance with GCP, Schedule Y (Drugs and Cosmetic Act, 1940 and any amendments therein) and ethical guidelines for biomedical research on human participants (Indian Council of Medical Research, 2006) at department of Clinical Pharmacology and Therapeutics, Nizam's Institute of Medical Sciences, Hyderabad. Written Informed Consent was taken before subjects were enrolled into the study.

Both gender aged between 18 to 65 years with a documented type II Diabetes Mellitus of $\geq$ two years duration were included into the study.

All procedures were performed in a sound proof temperature controlled room. Brachial blood pressure was recorded in duplicate in the nondominant arm using a validated Mercury sphygmomanometer. Radial arterial waveforms (20 cardiac cycles) were recorded with a highfidelity tonometer and validated transfer function was then used to generate a corresponding central aortic pressure waveform. An averaged composite radial waveform was calculated from which specially designed software (Sphygmo Cor TM; PWV Inc., Australia, version 8) derived an aortic BP waveform, in real time, using a validated transfer function algorithm. Augmentation Pressure (AP) is quantified as the amount of pressure added to the systolic pressure peak based on the reflected wave and Augmentation index AIx) calculated, as the difference between the second systolic peak and inflection point, expressed in percentage. An average of nearest two measurements was taken.

Plasma glutathione estimation was determined by using Ellman's method, where thiol group of glutathione reacts with 5, 5'-dithio-bis (2-nitrobenzoic acid) to give golden yellow colour complex measured at $412 \mathrm{~nm} .{ }^{22}$ Serum Malondialdehyde (MDA) was measured by using trichloroacetic acid and thiobarbituric acid and absorbance of the supernatant was read at $540 \mathrm{~nm}$ against blank. ${ }^{23}$ Nitric Oxide (NO) was measured in form of total (Nitrite/ Nitrate) in human serum by employing colorimetric detection with Griess reagents. ${ }^{24,25}$ Human high-sensitivity CRP C-Reactive Protein was measured by using commercially available ELISA kits manufactured by Calbiotech Inc, USA as per the manufacturers' recommendation. 
The study was done in a 60 type 2 Diabetes Mellitus subjects. All changes represent absolute differences, rather than percentage. All values represent mean \pm SD. $p$ value of less than 0.05 was statistically significant.

\section{RESULTS}

\section{Baseline clinical characteristics}

A total of 60 type II diabetes mellitus subjects participated in this study conducted at department of clinical pharmacology and therapeutics, Nizam's Institute of Medical Sciences, Hyderabad, India. The baseline clinical characteristics of participants are summarized in Table 1. Out of there 60 subjects 14 were with Coronary Artery Disease (CAD). As Endothelial Function is age dependent the study population was sub grouped in to 3 groups based on age (20-40 years, $40-60$ years and $>60$ years).

Table 1: Demographic characters of the study population.

\begin{tabular}{|llll|}
\hline Character & $\begin{array}{l}\text { Total } \\
\text { Group } \\
\mathbf{n = 6 0}\end{array}$ & $\begin{array}{l}\text { Type II } \\
\text { DM } \\
\mathbf{n = 4 4}\end{array}$ & $\begin{array}{l}\text { CAD } \\
\mathbf{n}=\mathbf{1 6}\end{array}$ \\
\hline Age (years) & $48.3 \pm 8.85$ & $47.4 \pm 8.91$ & $50.7 \pm 8.21$ \\
\hline Male:Female ratio & $46: 14$ & $35: 11$ & $11: 3$ \\
\hline $\begin{array}{l}\text { Coronary artery } \\
\text { disease(number) }\end{array}$ & 16 & -- & -- \\
\hline Smoker(number) & 08 & 7 & 5 \\
\hline Alcoholic(number) & 10 & 3 & 3 \\
\hline
\end{tabular}

Table 2: Inflammatory marker (high sensitive C - Reactive Protein), oxidative stress (malondialdehyde and glutathione), total (nitrite/ nitrate) and endothelial function (augmentation pressure, augmentation index in three different groups.

\begin{tabular}{|llll|}
\hline Parameter & $\begin{array}{l}\text { Total group } \\
(\mathbf{n}=\mathbf{6 0})\end{array}$ & $\begin{array}{l}\text { Diabetes mellitus } \\
(\mathbf{n}=\mathbf{4 4})\end{array}$ & $\begin{array}{l}\text { Coronary artery disease } \\
(\mathbf{n}=\mathbf{1 6})\end{array}$ \\
\hline hs CRP $^{@}(\mathrm{mg} / \mathrm{L})$ & $8.61 \pm 1.94$ & $5.73 \pm 2.02$ & $5.28 \pm 1.73$ \\
\hline Glutathione $^{@}(\mu \mathrm{mol} / \mathrm{L})$ & $235.46 \pm 80.89$ & $227.35 \pm 74.04$ & $257.76 \pm 96.41$ \\
\hline Malondialdehyde $^{\circledR}($ nanomol/ml $)$ & $5.92 \pm 1.55$ & $5.89 \pm 1.53$ & $6.0 \pm 1.65$ \\
\hline Total $\left(\right.$ Nitrite/ Nitrate) $^{@}(\mu \mathrm{mol} / \mathrm{L})$ & $23.05 \pm 2.51$ & $23.25 \pm 5.59$ & $22.49 \pm 5.47$ \\
\hline Augmentation Pressure* $\left(\mathrm{mm}\right.$ of Mercury) $^{*}$ & $13.75 \pm 4.98$ & $12.89 \pm 5.19$ & $16.13 \pm 3.47$ \\
\hline Augmentation Index ${ }^{\#}($ Ratio $)$ & $32.53 \pm 7.26$ & $29.8 \pm 5.68$ & $40.01 \pm 5.74$ \\
\hline
\end{tabular}

@ $\mathrm{p}>0.05$ between all the three groups. * $\mathrm{p}=0.02$ between diabetes mellitus and coronary heart disease. \# $\mathrm{p}=0.04$ between total group and coronary artery disease and $\mathrm{p}=0.0001$ between diabetes mellitus and coronary artery disease

Table 3: Inflammatory marker (high sensitive C - Reactive Protein), oxidative stress (malondialdehyde and glutathione), total (nitrite/ nitrate) and endothelial function (augmentation pressure, augmentation index in three age groups.

\begin{tabular}{|llll|}
\hline Parameter & $\begin{array}{l}\text { Age group 20-40 } \\
\text { years }(\mathbf{n}=\mathbf{1 3})\end{array}$ & $\begin{array}{l}\text { Age group 40-60 years } \\
(\mathbf{n}=\mathbf{4 1})\end{array}$ & $\begin{array}{l}\text { Age group }>\text { 60 } \\
\text { years }(\mathbf{n}=\mathbf{0 6})\end{array}$ \\
\hline hs CRP@ $(\mathrm{mg} / \mathrm{L})$ & $5.92 \pm 1.64$ & $5.65 \pm 2.01$ & $4.89 \pm 2.31$ \\
\hline Glutathione@ $(\mu \mathrm{mol} / \mathrm{L})$ & $225.12 \pm 62.13$ & $235.36 \pm 88.67$ & $247.88 \pm 69.22$ \\
\hline Malondialdehyde@ (nanomol/ml) & $5.83 \pm 1.72$ & $5.77 \pm 1.48$ & $6.74 \pm 1.36$ \\
\hline Total $($ Nitrite/ Nitrate) @ $(\mu \mathrm{mol} / \mathrm{L})$ & $25.01 \pm 4.05$ & $22.94 \pm 5.23$ & $20.51 \pm 8.89$ \\
\hline Augmentation Pressure* $(\mathrm{mm}$ of Mercury) & $10.59 \pm 3.34$ & $14.41 \pm 5.22$ & $15.83 \pm 3.92$ \\
\hline Augmentation Index@ (ratio) & $29.67 \pm 7.97$ & $32.90 \pm 7.04$ & $34.83 \pm 7.28$ \\
\hline
\end{tabular}

@ $\mathrm{p}>0.05$ between all the three groups. * $\mathrm{p}=0.0096$ age group 20-40 years and age group $>60$ years

Levels of inflammatory marker (high sensitive C Reactive Protein), oxidative stress (malondialdehyde and glutathione), total (nitrite/ nitrate) and endothelial function (augmentation pressure, augmentation index in the three groups of the study. Inflammatory status (high sensitive C reactive protein $(\mathrm{mg} / \mathrm{L})$ in total group $8.61 \pm 1.94$; diabetes mellitus $5.73 \pm 2.02$ and coronary artery disease $5.28 \pm 1.73$ ), oxidative stress measured by glutathione $(\mu \mathrm{mol} / \mathrm{L})$ in total group $235.46 \pm 80.89$; diabetes mellitus $227.35 \pm 74.04$ and coronary artery disease $257.76 \pm 96.41$ ) and malondialdehyde (nanomol/ml) in total group $5.92 \pm 1.55$; diabetes mellitus $5.89 \pm 1.53$ and coronary artery disease $6.0 \pm 1.65$ ) and nitric oxide as total (nitrite/ nitrate) $(\mu \mathrm{mol} / \mathrm{L})$ in total group $23.05 \pm 2.51$; diabetes mellitus 23.25 \pm 5.59 and coronary artery disease 22.49 \pm 5.47 ) showed no statistical difference between total group, Diabetes Mellitus Group and Coronary Artery Group. 
Augmentation Pressure (mm of mercury) did not show any statistical difference $(\mathrm{p}>0.05)$ when compared between total group (13.75 \pm 4.98$)$, diabetes mellitus group $(12.89 \pm 5.19)$ and coronary artery group $(16.13 \pm 3.47)$. But augmentation pressure showed statistical difference $(\mathrm{p}=0.02)$ when compared between diabetes mellitus group and coronary artery group. Augmentation index (ratio) did not show any statistical difference when compared between total group $(32.53 \pm 7.26)$ and diabetes mellitus group (12.89 \pm 5.19$)$. But Augmentation Index is statistical difference $(\mathrm{p}=0.04)$ between Total group and coronary heart disease and $\mathrm{p}=0.0001$ between diabetes mellitus and coronary heart disease.

Levels of Inflammatory Marker (High sensitive C Reactive Protein), oxidative stress (malondialdehyde and glutathione), total (nitrite/ nitrate) and endothelial function (augmentation pressure, augmentation index when the total study population is divided into different age groups. In all the three age groups High sensitive $\mathrm{C}$ - Reactive Protein (20-40 years- 5.92 \pm 1.64 , Age Group 40-60$5.65 \pm 2.01$ years and $>60$ years- $4.89 \pm 2.31$ ), Oxidative stress in form of Glutathione (20-40 years- 225.12 \pm 62.13 , age group 40-60-235.36 \pm 88.67 Years and >60 years$247.88 \pm 69.22)$, and malondialdehyde (20-40 years$5.83 \pm 1.72$, age group 40-60-5.77 \pm 1.48 years and $>60$ Years- 6.74 \pm 1.36 ), and nitric oxide as total (nitrite/ nitrate) (20-40 years- 25.01 \pm 4.05 , age group 40-60-22.94 \pm 5.23 years and $>60$ years- $20.51 \pm 8.89)$, did not show any statistical difference $(\mathrm{p}>0.05)$. The same pattern was seen with augmentation pressure (20-40 years-10.59 \pm 3.34 , age group 40-60- $14.41 \pm 5.22$ years and $>60$ years$15.83 \pm 3.92)$. While comparing augmentation index there was statistical difference between age group 20-40 $(29.67 \pm 7.97)$ years and age group (>60 years $34.83 \pm 7.28)$.

\section{DISCUSSION}

In 1990, endothelial dysfunction was first described in human hypertension in the forearm vasculature. Impairment of vasodilatation has also been described in type 1 and type 2 diabetes, coronary artery disease, congestive heart failure, and chronic renal failure. The pathophysiology of endothelial dysfunction is complex and involves multiple mechanisms.

The results from this study confirm that diabetes mellitus subjects with CAD are having a significant Endothelial dysfunction when compared to subjects with diabetes mellitus alone. Subjects with diabetes mellitus showed lesser levels of glutathione, total nitrite/nitrate, elevated levels of MDA and hS CRP levels in our study. In spite of no statistical difference between the Diabetes Mellitus subjects with CAD and without CAD in above markers, Augmentation Pressure and Augmentation Index measures of Endothelial dysfunction have varied significantly between these groups. Findings from our study are concurring with results from Paola Gargiulo et al, who found that Diabetic patients with and without CAD show significantly impaired peripheral vascular function compared to non-diabetic patients without CAD ${ }^{26} \mathrm{ED}$ in diabetic patients without CAD is comparable to patients with CAD without DM. In another study by Gissette Reyes-Soffer et al, showed patients with CAD, the concomitant presence of T2DM is independently associated with greater ED. ${ }^{27}$

In diabetes, various mechanisms can trigger endothelial dysfunction. Conditions like insulin resistance, as seen in type 2 diabetes where insulin signalling is altered, hyperglycemia leads to advanced glycation end products (AGE), which extinguish Nitric Oxide (NO) and impair endothelial function. ${ }^{28}$ AGE induce ROS and promote vascular inflammation, with enhanced expression of interleukin-6, VCAM-1, and MCP-1. ${ }^{29}$ This forms a vicious circle in conditions like diabetic nephropathy, as renal failure delays the clearance of AGE, further promoting vascular and renal injury. ${ }^{30}$ Acute hyperglycemia by itself can reduce NO and attenuate endothelium-dependent vasodilation in humans in vivo. ${ }^{31}$

Diabetes Mellitus regulation of NO metabolism is particularly important, since the activation of eNOS has been demonstrated to be under the insulin control. ${ }^{32,33}$ In pathological conditions, like diabetes mellitus, NOX activity and superoxide production are increased. ${ }^{34}$ Oxidative stress plays an important role in the development of insulin resistance and both micro- and macro-vascular diabetic complications. ${ }^{35}$ Diabetes Mellitus is associated with an impairment of cellular autophagy. ${ }^{36}$ Proinflammatory status of the vessel wall is directly linked to Oxidative excess. NO bioavailability is reduced by Inflammation and $\mathrm{C}$-reactive protein (CRP) has been implicated to decrease eNOS activity.

Acute inflammatory states have been implicated to impair endothelium-dependent vasodilatation through inflammatory mediators like tumour necrosis factor- $\alpha$ $(\mathrm{TNF}-\alpha)$ and decrease eNOS expression in ECs. ${ }^{37}$ Diabetes is considered to be a systemic inflammatory state that can impair endothelial function and contribute to atherosclerosis. ${ }^{38}$ In diabetic patients there is an increase in circulating levels of inflammatory markers like $\mathrm{C}$ reactive protein, TNF- Alfa, and intercellular adhesion molecule1. ${ }^{39,40}$ This increase in inflammatory markers is considered as a double edged sword as on one hand this is predictor of increased cardiovascular risk in diabetic patients and on the other hand, they also relate to the incidence of diabetes mellitus. ${ }^{41,42}$

In Diabetes Mellitus Endothelial dysfunction contributes to cardiovascular morbidity. ${ }^{43}$ Others mechanisms contributing to development of diabetes-induced endothelial dysfunction include prostanoid vasoconstrictors production and increased oxidative degradation of NO. ${ }^{44}$ Atherogenesis and increases vascular resistance are a result of deficient NO production along with other mechanisms of NO deficiency, increased oxidative degradation, and NO deficiency caused by asymmetric dimethylarginine (ADMA) finally 
contributing to Cardiovascular morbidity and mortality in Diabetes Mellitus. ${ }^{45,46}$

Diabetes Mellitus individuals are at increased risk for development of cardiovascular disease (CVD). There is profound association between like hood for development of atherosclerotic plaque formation and Diabetes Mellitus although the exact mechanisms of association between these two are not completely defined. Reduced NO and increased oxidative stress may activate matrix metalloproteinases (MMP), mainly MMP-2 and MMP-9, which weaken the fibrous cap. Thrombogenicity and its severity are contributed by reduced NO and inhibition of platelet aggregation. ${ }^{31}$ In type 1 or type 2 diabetes CVD is the primary cause of death and it accounts for highest component of health care expenditures in people with diabetes. ${ }^{47,48}$ In prediction of stroke and cerebrovascular disease in CAD, Diabetes Mellitus is considered to be a strong independent risk factor. ${ }^{49}$

Reduced NO bioavailability, increased oxidant excess, and expression of adhesion molecules contributes to Endothelial Dysfunction both for its initiation and progression of atherosclerotic plaque formation and finally to triggering of cardiovascular events. Because endothelial dysfunction is an early event, it may be of prognostic value. As the measures of endothelial dysfunction become clinically applicable, this may translate into improved methods of risk assessment that help in predicting, preventing and treating cardiovascular disease.

Funding: No funding sources

Conflict of interest: None declared

Ethical approval: The study was approved by the Institutional Ethics Committee

\section{REFERENCES}

1. World Health Organization, Global Report on Diabetes. Geneva, 2016.

2. Wild S, Roglic G, Green A, Sicree R, King H. Global prevalence of diabetes: Estimates for the year 2000 and projections for 2030. Diabetes Care. 2004;27(5):104753.

3. Cho NH. International Diabetes Foundation. Diabetes Atlas. Seventh Edition. Chapter 4.6. South East Asia. $\mathrm{Ph}: 90-93$.

4. Taddei S, Virdis A, Mattei P, Ghiadoni L, Sudano I, Salvetti A. Defective L-arginine-nitric oxide pathway in offspring of essential hypertensive patients. Circulation. 1996;94:1298-303.

5. Suwaidi JA, Hamasaki S, Higano ST, Nishimura RA, Holmes DR, Lerman A. Long-term follow-up of patients with mild coronary artery disease and endothelial dysfunction. Circulation. 2000;101:948-54.

6. Lerman A, Burnett JC. Intact and altered endothelium in regulation of vasomotion. Circulation. 1992;86(3):12-9.

7. Deanfield JE, Halcox JP, Rabelink TJ. Endothelial function and dysfunction: testing and clinical relevance, Circulation. 2007;115(10):1285-95.
8. Napoli C, Ignarro LJ. Nitric oxide and pathogenic mechanisms involved in the development of vascular diseases, Archives of Pharmacal Research. 2009;32(8):1103-8.

9. Magenta A, Greco S, Gaetano C. Oxidative stress and microRNAs in vascular diseases, International Journal of Molecular Sciences. 2013;14(9):17319-46.

10. Muniyappa R, Quon MJ. Insulin action and insulin resistance in vascular endothelium. Current Opinion in Clinical Nutrition \& Metabolic Care. 2007 Jul $1 ; 10(4): 523-30$.

11. Ware JA, Heistad DD, Flier J, Salzman E, Weller P. Platelet-endothelium interactions. The New England Journal of Medicine. 1993;328(9):628-35.

12. Paneni F, Beckman JA, Creager MA, Cosentino F. Diabetes and vascular disease: pathophysiology, clinical consequences, and medical therapy: part I. European heart journal. 2013 May 2;34(31):2436-43.

13. Keaney JF, Massaro JM, Larson MG, Vasan RS, Wilson PW, Lipinska I, et al. Heritability and correlates of intercellular adhesion molecule- 1 in the Framingham Offspring Study. Journal of the American College of Cardiology. 2004 Jul 7;44(1):168-73.

14. Festa A, D'agostino R, Howard G, Mykkänen L, Tracy RP, Haffner SM. Chronic subclinical inflammation as part of the insulin resistance syndrome. Circulation. 2000 Jul 4;102(1):42-7.

15. Pradhan AD, Manson JE, Rifai N, Buring JE, Ridker PM. C-reactive protein, interleukin 6 , and risk of developing type 2 diabetes mellitus. Jama. 2001 Jul 18;286(3):32734.

16. Schulze MB, Rimm EB, Li T, Rifai N, Stampfer MJ, Hu FB. C-reactive protein and incident cardiovascular events among men with diabetes. Diabetes care. 2004 Apr 1;27(4):889-94.

17. Duncan BB, Schmidt MI, Pankow JS, Ballantyne CM, Couper D, Vigo A, Hoogeveen R, Folsom AR, Heiss G. Low-grade systemic inflammation and the development of type 2 diabetes. Diabetes. 2003 Jul 1;52(7):1799-805.

18. Siti HN, Kamisah Y, Kamsiah J. The role of oxidative stress, antioxidants and vascular inflammation in cardiovascular disease (a review). Vascular pharmacology. 2015 Aug 31;71:40-56.

19. Fox CS, Coady S, Sorlie PD. Trends in cardiovascular complications of diabetes. JAMA, J. Am. Med. Assoc. 2004;292:2495-9.

20. Fichtlscherer S, Breuer S, Zeiher AM. Prognostic value of systemic endothelial dysfunction in patients with acute coronary syndromes: further evidence for the existence of the "vulnerable" patient. Circulation. 2004;110:1926-32.

21. Targonski PV, Bonetti PO, Pumper GM, Higano ST, Holmes DR, Lerman A. Coronary endothelial dysfunction is associated with an increased risk of cerebrovascular events. Circulation. 2003;107:2805-9.

22. Rahman I, Kode A, Biswas SK. Assay for quantitative determination of Glutathione and disulfide levels using enzymatic recycling method. Nature Protocols. 2008; $1: 3159-65$.

23. Vidyasagar J, Karunakar N, Reddy MS, Rajnarayana K, Surender T, Krishna DR. Oxidative stress and antioxidant status in acute organophosphorous insecticide poisoning. Indian journal of Pharmacology. 2004 Mar 1;36(2):76. 
24. Miranda KM, Espey MG, Wink DA. A rapid, simple spectrophotometric method for simultaneous detection of nitrate and nitrite. Nitric oxide. 2001 Feb 1;5(1):62-71.

25. Sastry KV, Moudgal RP, Mohan J, Tyagi JS, Rao G. Spectrophotometric determination of serum nitrite and nitrate by copper-cadmium alloy. Analytical biochemistry. 2002 Jul 1;306(1):79-82.

26. Gargiulo P, Marciano C, Savarese G. Endothelial dysfunction in type 2 diabetic patients with normal coronary arteries. April 30, 2013;165(1):67-71.

27. Reyes-Soffer G, Holleran S, Di Tullio MR, Homma S, Boden-Albala B, Ramakrishnan R, et al. Endothelial function in individuals with coronary artery disease with and without type 2 diabetes mellitus. Metabolism. 2010 Sep 30;59(9):1365-71.

28. Bucala R, Tracey KJ, Cerami A. Advanced glycosylation products quench nitric oxide and mediate defective endothelium dependent vasodilatation in experimental diabetes. J Clin Invest. 1991;87:432-8.

29. Zhang L, Zalewski A, Liu Y, Mazurek T, Cowan S, Martin JL, et al. Diabetes-induced oxidative stress and low-grade inflammation in porcine coronary arteries. Circulation. 2003;108:472-8.

30. Makita Z, Radoff S, Rayfield EJ, Yang Z, Skolnik E, Delaney V, et al. Advanced glycosylation end products in patients with diabetic nephropathy. $\mathrm{N}$ Engl J Med. 1991;325:836-42.

31. Williams SB, Goldfine AB, Timimi FK, Ting HH, Roddy MA, Simonson DC, et al. Acute hyperglycemia attenuates endothelium-dependent vasodilate on in humans in vivo. Circulation. 1998;97:1695-701.

32. Muniyappa R, Quon MJ. Insulin action and insulin resistance in vascular endothelium, Current Opinion in Clinical Nutrition and Metabolic Care. 2007;10(4):52330.

33. Vicent D, Ilany J, Kondo T, Naruse K, Fisher SJ, Kisanuki YY, et al. The role of endothelial insulin signaling in the regulation of vascular tone and insulin resistance J Clin Invest. 2003 May 1;111(9):1373-80.

34. San Martin A, Du P, Dikalova A, Lassègue B, Aleman M, Góngora MC, et al. Reactive oxygen species-selective regulation of aortic inflammatory gene expression in Type 2 diabetes. American Journal of Physiology-Heart and Circulatory Physiology. 2007 May 1;292(5):H207382 .

35. Gao L, Mann GE. Vascular NAD (P) H oxidase activation in diabetes: a double-edged sword in redox signalling. Cardiovascular research. 2009 Jan 29;82(1):920.

36. Giacco F, Brownlee M. Oxidative stress and diabetic complications. Circulation research. 2010 Oct 29;107(9):1058-70.

37. Zhang J, Patel JM, Li YD, Block ER. Proinflammatory cytokines downregulate gene expression and activity of constitutive nitric oxide synthase in porcine pulmonary artery endothelial cells. Research communications in molecular pathology and pharmacology. 1997 Apr;96(1):71-87.
38. Beckman JA, Paneni F, Cosentino F, Creager MA. Diabetes and vascular disease: pathophysiology, clinical consequences, and medical therapy: part II. European heart journal. 2013 Apr 26;34(31):2444-52.

39. Keaney JF, Massaro JM, Larson MG, Vasan RS, Wilson PW, Lipinska I, et al. Heritability and correlates of intercellular adhesion molecule-1 in the Framingham Offspring Study. Journal of the American College of Cardiology. 2004 Jul 7;44(1):168-73.

40. Festa A, D'agostino R, Howard G, Mykkänen L, Tracy RP, Haffner SM. Chronic subclinical inflammation as part of the insulin resistance syndrome. Circulation. 2000 Jul 4;102(1):42-7.

41. Schulze MB, Rimm EB, Li T, Rifai N, Stampfer MJ, Hu FB. C-reactive protein and incident cardiovascular events among men with diabetes. Diabetes care. 2004 Apr 1;27(4):889-94.

42. Duncan BB, Schmidt MI, Pankow JS, Ballantyne CM, Couper D, Vigo A, et al. Low-grade systemic inflammation and the development of type 2 diabetes. Diabetes. 2003 Jul 1;52(7):1799-805.

43. Miyazaki H, Matsuoka H, Cooke JP, Usui M, Ueda S, Okuda S, et al. Endogenous nitric oxide synthase inhibitor. Circulation. 1999 Mar 9;99(9):1141-6.

44. Tesfamariam B, Brown ML, Cohen RA. 15Hydroxyeicosatetraenoic acid and diabetic endothelial dysfunction in rabbit aorta. Journal of cardiovascular pharmacology. 1995 May 1;25(5):748-55.

45. Valkonen VP, Päivä H, Salonen JT. Risk of acute coronary events and serum concentration of asymmetrical dimethylarginine. Lancet. 2001;358:21278.

46. Paterson AD, Rutledge BN, Cleary PA, Lachin JM, Crow RS. The effect of intensive diabetes treatment on resting heart rate in type 1 diabetes: The Diabetes Control and Complications Trial/Epidemiology of Diabetes Interventions and Complications study. Diabetes Care. 2007;30:2107-12.

47. Hogan P, Dall T, Nikolov P. Economic costs of diabetes in the US in 2002. Diabetes Care. 2003;26:917-32.

48. Lehto S, Ronnemaa T, Pyorala K, Laakso M. Predictors of stroke in middle-aged patients with non-insulindependent diabetes. Stroke. 1996;27:63-8.

49. Uemura S, Matsushita H, Li W, Glassford AJ, Asagami $\mathrm{T}$, Lee $\mathrm{KH}$, et al. Diabetes mellitus enhances vascular matrix metalloproteinase activity: Role of oxidative stress. Circ Res. 2001;88:1291-8.

Cite this article as: Reddy $\mathrm{CP}$, Chiranjeevi UK, Chandrasekhar N, Kishore KK, Krishna PV. Correlation between endothelial dysfunction, inflammatory status, oxidative stress and total (nitrite/ nitrate) in subjects with diabetes mellitus type 2. Int J Basic Clin Pharmacol 2017;6:2317-22. 